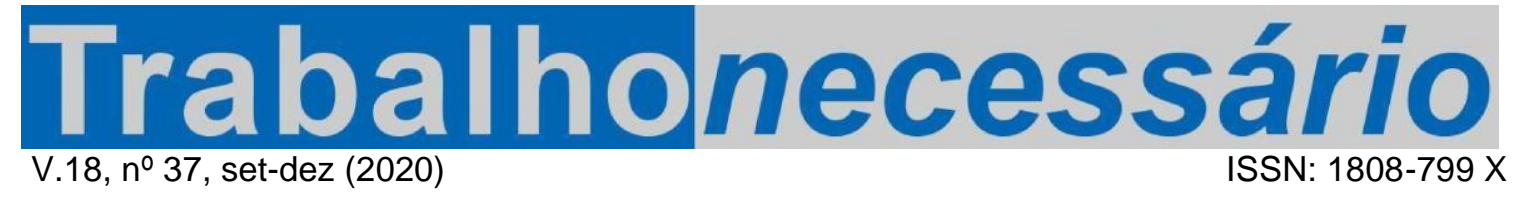

\title{
MOVIMENTO DOS ATINGIDOS POR BARRAGENS (MAB): "DEFENDER A AMAZÔNIA É DEFENDER A VIDA"1
}

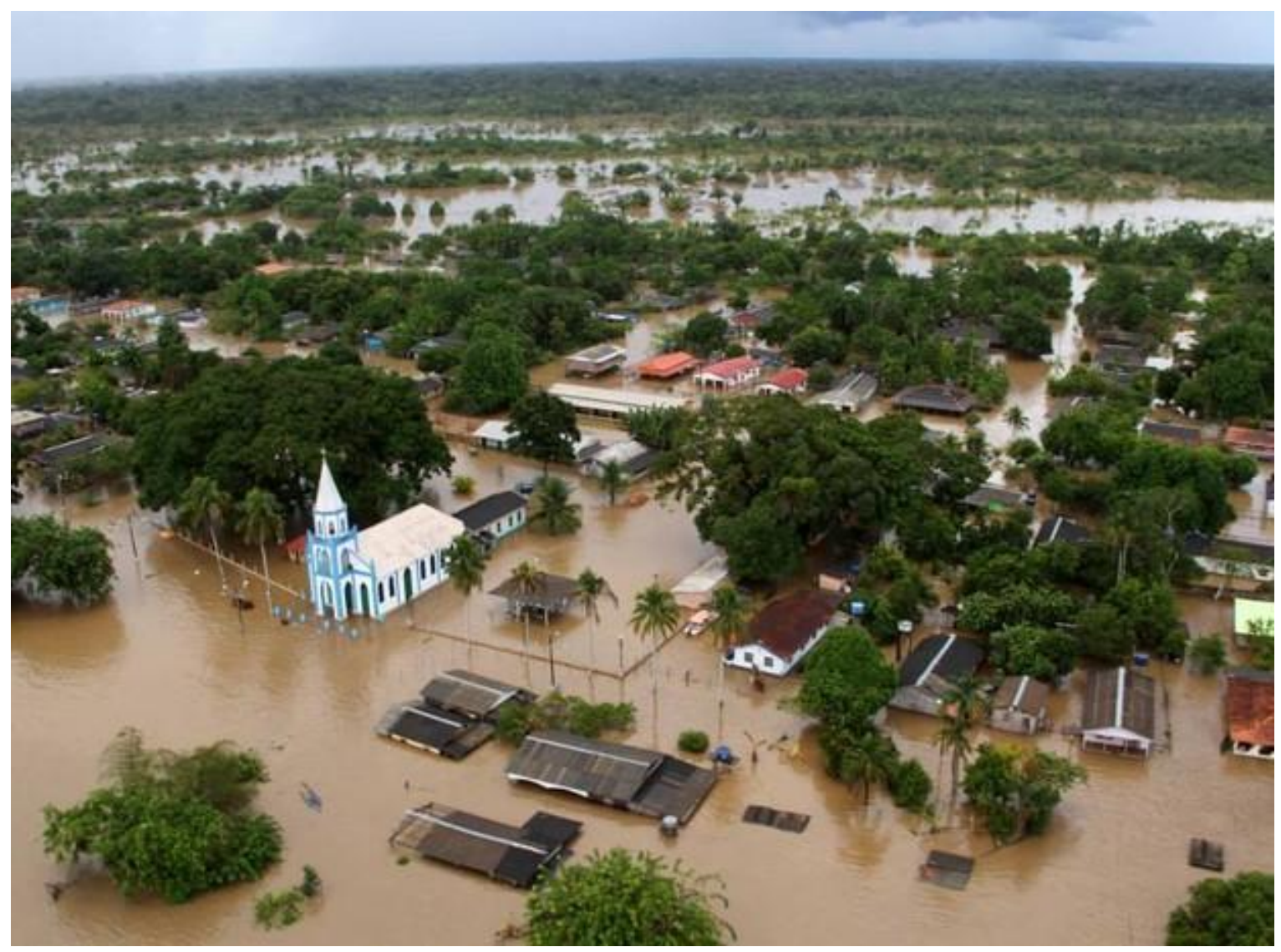

Distrito de São Carlos do Jamari totalmente inundado pela cheia do rio Madeira, em 2014 Fonte: http://rondoniadigital.com

\section{Entrevista a Océlio Muniz, membro da Coordenação Estadual do MAB (RO), realizada por Mahalia Aquino ${ }^{2}$ e William Kennedy do Amaral Souza ${ }^{3}$}

\footnotetext{
${ }^{1}$ Entrevista recebida em 02/07/2020. Aprovada pelos editores em 21/07/2020. Publicada em 25/09/2020. DOI: http://doi.org/10.22409/tn.v18i37.43349.

${ }^{2}$ Mestre em Educação pela Universidade Federal do Estado do Rio de Janeiro - UNIRIO. Professora de Geografia e doutoranda em Educação pela Universidade Federal Fluminense (Rio de Janeiro, Brasil), orientada pela Prof. ${ }^{a}$ Dr. ${ }^{\text {a }}$ Zuleide S. da Silveira. E-mail: mahaliagcaquino@gmail.com ORCID: 0000-0002-1392-8487. Lattes: http://lattes.cnpq.br/1716949253761324.

${ }^{3}$ Doutor em Educação pela Universidade Federal Fluminense (UFF). Professor de Sociologia e Sociologia Rural no Instituto Federal de Educação de Rondônia (IFRO) - Brasil. E-mail: william.souza@ifro.edu.br. ORCID: 0000-0001-6271-9422.

Lattes: http://lattes.cnpq.br/0703023274968708
} 
Em reunião ministerial no dia 22 de abril de 2020, Ricardo Salles, Ministro do Meio Ambiente, afirmou ser necessário "passar as reformas infra legais de desregulamentação, simplificação" de leis, normatizações e regras ambientais e do uso de seus recursos, se aproveitando da atenção da mídia e da sociedade voltada majoritariamente para a questão do COVID-19. Para ele, esse seria um momento oportuno para "ir passando a boiada e mudando todo o regramento e simplificando normas. (...). Agora é hora de unir esforços pra (sic) dar de baciada a simplificação, é de regulatório que nós precisamos, em todos os aspectos"4.

A fala do Ministro do Meio Ambiente nos reafirma que no governo Bolsonaro, o Brasil vive um drama não apenas político, mas econômico, social e ambiental. O cenário se apresenta como caótico em meio à paralisia do Governo Federal na contenção e tratamento à pandemia do vírus COVID-19. A insistência em manter um discurso anticientífico e irracional nas tomadas de decisão, os ataques às mídias de informação e formação de opinião pública têm o intuito de mascarar o interesse do Estado em executar pacotes de salvamento a bancos e empresas privadas, buscando soluções para a economia estagnada em detrimento da saúde coletiva da população. Essas ameaças recaem, de forma mais adensada, nos grupos mais vulneráveis economicamente e nas comunidades tradicionais, que se encontram expostas a um duplo risco: o de perder suas vidas pela irresponsabilidade do poder público e o de perder seus territórios em prol da soberania produtiva capitalista e seu desenvolvimento insaciável.

Vivemos um período marcado pela ascensão de uma extrema direta de cunho autoritário e antidemocrático, que se pauta em ideais fascistas - xenofóbicos, racistas e machistas -, e ataca ferozmente os direitos historicamente conquistados pela classe trabalhadora e os seus respectivos territórios e modos de vida, a partir de uma moral e fé cristã. Essa guinada está ancorada em velhas novidades e em discursos conhecidos de outras épocas, que se repetem em dados períodos históricos da sociedade, marcados por um aspecto em comum: originam-se como resposta da classe dominante às crises cíclicas do capitalismo (CUEVA, 1989) ${ }^{5}$.

\footnotetext{
${ }^{4}$ Divulgada ao público pelo Ministro do STF Celso de Mello no dia 22 de maio de 2020. Fonte: <https://g1.globo.com/politica/noticia/2020/05/22/ministro-do-meio-ambiente-defende-passar-aboiada-e-mudar-regramento-e-simplificar-normas.ghtml>, acesso em: 04 de junho de 2020, as 10:42. ${ }^{5}$ CUEVA, Augustín. A guinada conservadora. In: CUEVA, Augustín (Org.). Tempos conservadores: a direitização no Ocidente e na América Latina. São Paulo: Hucitec, 1989.
} 
A construção de barragens faz parte da dinâmica econômico-produtiva das commodities, fornecendo suportes espaciais e infra estruturais para a instalação de mega empreendimentos, sejam eles para fins energéticos - como o caso de Santo Antônio Energia em Rondônia -, ou para a retenção de rejeitos originários do processo de beneficiamento do minério, que dominam paisagens, como em Minas Gerais. Para que essas construções se efetivem, a água torna-se o elemento fundamental, isso explica o porquê sua construção se dá, "[...] sempre, nos leitos de rios e córregos, destruindo assim de forma irreversível estes cursos d'água" (JUSTIÇA GLOBAL, 2016, p. $7^{6}$ ). Além da expropriação dos recursos naturais, as barragens submetem diversos grupos sociais à condição de subalternidade, retirando seus direitos historicamente adquiridos de existência e subsistência a partir de seus territórios e na relação intrínseca a natureza.

Ocorre então uma violência ambiental do capitalismo sobre os territórios e, com isso, desencadeia uma série de impactos socioambientais irreversíveis, como o crime ocorrido na bacia do Rio Doce (em 2015) e Paraopeba (em 2019). No caso da barragem de Fundão (Mariana - MG), sua operação iniciada em 2008 se dá no período em que o preço do minério de ferro atingiu o seu ápice. O licenciamento foi aprovado, mas com uma série de condicionantes que não foram sanadas. Possuía indícios de aumento do número de acidentes de trabalho, que já apontava para um despreparo em cumprir com os planos de segurança. Seu rompimento, em 2015, ocorre como consequência da queda no valor do minério no mercado financeiro, em meio à crise econômica mundial. Tal desastre destituiu os sujeitos de seus próprios espaços tradicionais de convívio, submergindo seus modos de vida e entes queridos sob um rio de lama (material estéril e de alta toxicidade), provocando um rompimento histórico entre o trabalho, as relações sociais e ambientais locais das comunidades atingidas.

A Revista Trabalho Necessário traz a entrevista a Océlio Muniz, membro da Coordenação Estadual do Movimento dos Atingidos por Barragens de Rondônia (MAB - RO). Océlio é nascido no Ceará, estado no qual foi atingido por barragem e que deu início a sua inserção no movimento há dez anos. Em Rondônia, contribui para a

\footnotetext{
${ }^{6}$ JUSTIÇA GLOBAL. Vale de lama: Relatório de inspeção em Mariana após o rompimento da barragem de rejeitos do Fundão, 2016. Disponível em: <http://conflitosambientaismg.lcc.ufmg.br/wpcontent/uploads/2016/01/Vale-de-Lama-Justic\%CC\%A7a-Global.pdf>. Acesso em: 29 jun. de 2020.
} 
construção do MAB no estado, com a tarefa de organização do movimento nas comunidades. A conversa foi realizada no dia 25 de maio de 2020, por meio digital ${ }^{7} \mathrm{e}$ conta com a apresentação de fotografias que evidenciam os processos de luta e mobilização popular do MAB nos territórios atingidos pela construção de grandes empreendimentos, como desvio de rios, barragens minerárias e hidroelétricas. Também há fotos do cotidiano de comunidades ribeirinhas e exemplos da grandeza dos rios amazônicos.

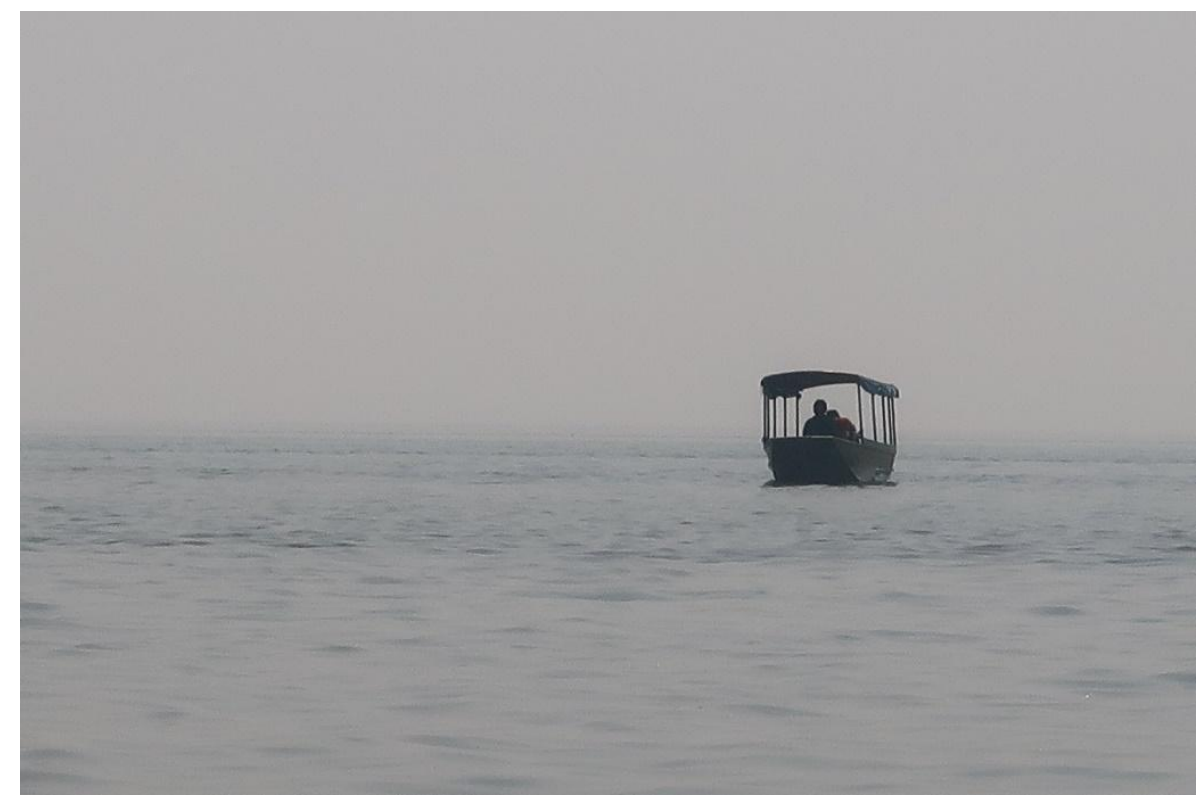

O barco na imensidão do rio Madeira.

Fonte: Foto de William Kennedy do Amaral Souza (2019).

Trabalho Necessário: No campo, os povos tradicionais e a classe trabalhadora vêm sofrendo com os crimes socioambientais em seus territórios e também com a crescente perda de direitos que foram conquistados historicamente. Como a questão ambiental se insere neste momento nas pautas de luta, mobilização e participação do Movimento dos Atingidos por Barragens (MAB)?

Océlio Muniz: Historicamente o MAB teve em suas pautas de luta a defesa do meio ambiente. Entendemos que a luta contra as barragens é a luta contra a destruição da natureza dos rios e das florestas, e temos isto como central. Na conjuntura atual, o Movimento tem debatido que defender a Amazônia é defender a vida. Em um

\footnotetext{
${ }^{7}$ Em cumprimento às medidas de isolamento social da pandemia do COVID-19 no período da realização da entrevista.
} 
momento em que as políticas ambientais estão sendo desmontadas pelo atual modelo econômico, o MAB vem somando forças com outras organizações para que as ações em defesa do meio ambiente sejam fortalecidas.

Trabalho Necessário: Diante do movimento predatório do capitalismo sobre os territórios das comunidades tradicionais, de que forma as mobilizações sociais são capazes de conter os avanços e os danos ambientais nesses espaços de interesses à exploração?

Océlio Muniz: Na nossa compreensão, há diversas lutas que podemos fazer! As lutas populares com consciência política em locais como comunidades indignas, comunidades ribeirinhas, pequenos produtores rurais, criando resistências locais, podem ser um elo central com a sociedade em defesa do território. Outras ações serão via mídias sociais e apoio da sociedade, com o povo urbano fazendo uma relação da importância de preservação da vida.

Trabalho Necessário: Qual a importância de trazer os grupos urbanos para a luta no campo? De que forma essa estratégia de luta amplia a participação e chama para uma luta coletiva?

Océlio Muniz: $O M A B$, historicamente, é um o movimento camponês de famílias atingidas por barragens de maioria ribeirinha. Mas no mesmo período, a maioria das barragens construídas no Brasil atinge também habitantes da área urbana, não só em Rondônia (que temos famílias atingidas na área urbana de Porto Velho RO e outros distritos que são que possuem famílias deslocadas). Então a estratégia do MAB também é a organização do público urbano. Para fortalecer a luta do $M A B$, entendemos que os atingidos por barragens não estão só nas zonas rurais. $\mathrm{Na}$ cidade temos dois perfis: um perfil composto por atingidos pelas hidrelétricas (que atingem o público urbano deslocado [reassentado]) e o outro perfil são famílias da periferia que pagam uma tarifa de luz que se configura como a $5^{\underline{a}}$ tarifa mais cara do Brasil. Então movimento tem construído articulações urbanas no sentido de fazer a luta para que o setor elétrico brasileiro melhore o acesso à energia elétrica nas áreas urbanas e que a população urbana tem acesso à energia com tarifa social. Essa é 
uma das ações que o Movimento trabalha nas áreas urbanas. Com isso temos feito uma terceira análise de que a importância do público urbano na luta, na compreensão de que os atingidos por barragens, não estão sós, de que somos todos atingidos, porque a construção da barragem ela impacta os atingidos por barragens diretamente e os atingidos urbanos com a conta de luz, com o discurso de que a construção das hidrelétricas diminui a conta de luz da população em geral... E nos últimos anos o MAB tem se deparado com essa contradição que as famílias urbanas não diminuíram a conta de luz, pelo contrário, só tem aumentado. Então os debates que temos feito na área urbana é travar uma luta para que o acesso à luz e barata para todos e todas.

Trabalho Necessário: Qual a relação existente entre a mercantilização dos recursos naturais e o aumento na violência socioambiental?

Océlio Muniz: Quando o mercado e as empresas em geral visam à produção das commodities em primeiro lugar, sem pensar na vida das pessoas e no meio ambiente, essa relação se torna mercadoria e tudo em seu entorno vira comércio para geração de lucro. Com essa relação, se tornam inevitáveis os conflitos socioambientais com as comunidades e povos que defende a vida. Exemplo disso foram os grandes crimes de Mariana e Brumadinho, ambos em Minas Gerais. Onde o lucro está acima da vida. No Norte temos os exemplos dos complexos hidroelétricos de Belo Monte (localizada a $40 \mathrm{~km}$ acima da cidade de Altamira - PA) e Madeira (Porto Velho - RO), que seguiram a mesma cartilha do lucro acima de tudo e todas. Não termos conciliação! Os conflitos são inevitáveis. 


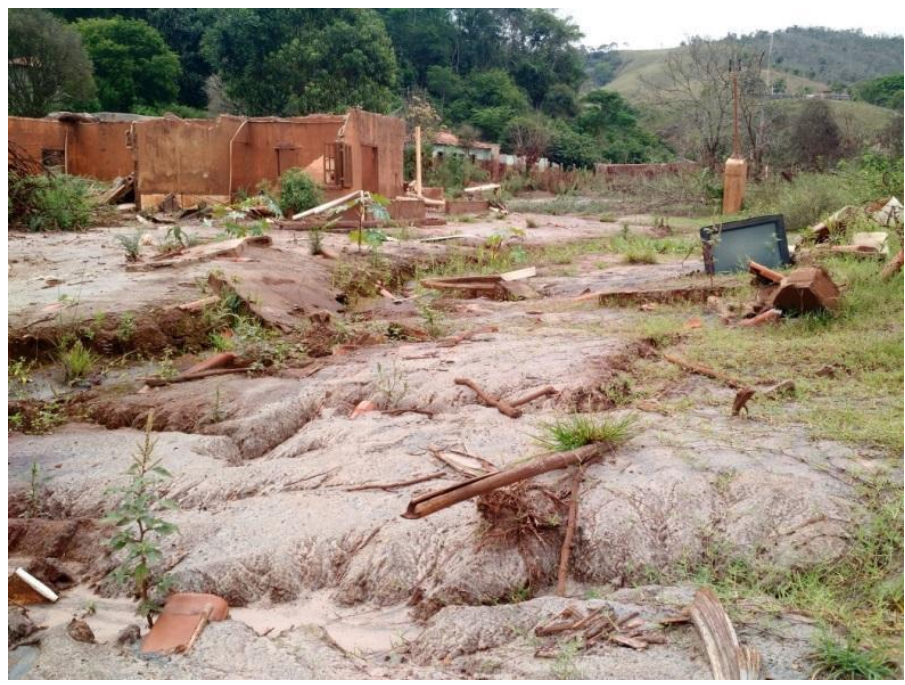

Paracatu de Baixo (Mariana - MG), segundo distrito atingido pelo rejeito minerário oriundo do rompimento da Barragem de Fundão, em 05 de novembro de 2015. Na memória da autora da foto, ainda estão presentes o cheiro forte ferroso do ar e a certeza de que nada pode ser mais destrutivo e devastador do que a ação do capital sobre a natureza.

Fonte: Mahalia Aquino (arquivo pessoal), registro realizado em 06 de novembro de 2016.

Trabalho Necessário: Usando o exemplo de Santo Antônio Energia, fale um pouco mais sobre a violência e os impasses com as empresas. As disputas e conflitos. De que forma a violência impacta diretamente nas comunidades? Como ela se manifesta localmente?

Océlio Muniz: Na luta do MAB na região de Santo Antônio, a barragem que fica mais perto de Porto Velho, teve grandes impasses enfrentamento contra Santo Antônio Energia em três questões:

I. a empresa não queria garantir o direito dos atingidos dizendo que não havia atingidos, que eram uma minoria. Então MAB foi para cima organizando as famílias no coletivo demonstrando para empresa que tinham atingidos. Então soltou de 200 famílias atingidas para quase três mil famílias e é um número que está crescendo porque empresa faz cálculos errados e tem famílias que hoje ainda, em 2020, estão sendo remanejadas. Por exemplo, o distrito em Jaci Paraná, é um conflito e uma disputa constante com a empresa, pois ela fez cálculos equivocados que o lago [da represa] subiu e mais famílias foram atingidas. Então as famílias têm esses constantes conflitos para que empresa garanta esse direito. O MAB entra nesse processo de organização social no coletivo para lutar por esse direito, que entra na segunda questão. 
II. Santo Antônio Energia sempre atuou para que o movimento não se fixasse nas comunidades impedindo a luta coletiva;

III. Quando fazemos a luta coletiva, garantimos um direito mais ampliado. Tem-se o direito e, assim, amplia o acesso a mais famílias. Esse direito dá as famílias mais firmeza quando essas passam pelo processo de luta coletiva. Os conflitos com a empresa sempre estão presentes, essas disputas, porque a empresa quer garantir suas propostas e as propostas da empresa sempre foram menos. O MAB busca no processo de luta e organização social no coletivo para obrigar que a empresa atenda a demanda integral das famílias atingidas por barragens.

Trabalho Necessário: O mercado global das commodities exerce fortes pressões sobre os territórios dos trabalhadores e trabalhadoras do campo. Quais são os impactos no trabalho e, em especial, no modo de vida das comunidades tradicionais?

Océlio Muniz: Nos últimos anos estamos enfrentando o avanço das commodities na região amazônica, tendo como consequência o aumento dos desmatamentos, exploração das terras indígenas e unidade de conservações. Com isso os povos são expulsos das suas terras e comunidades devido ao grande uso dos agrotóxicos usados pelas empresas e também invasões das terras por grileiros. Comunidades são destruídas, povos são forçados a fazer migrações internas e na maioria vão pra os centros urbanos e ficam sem teto e sem-terra.

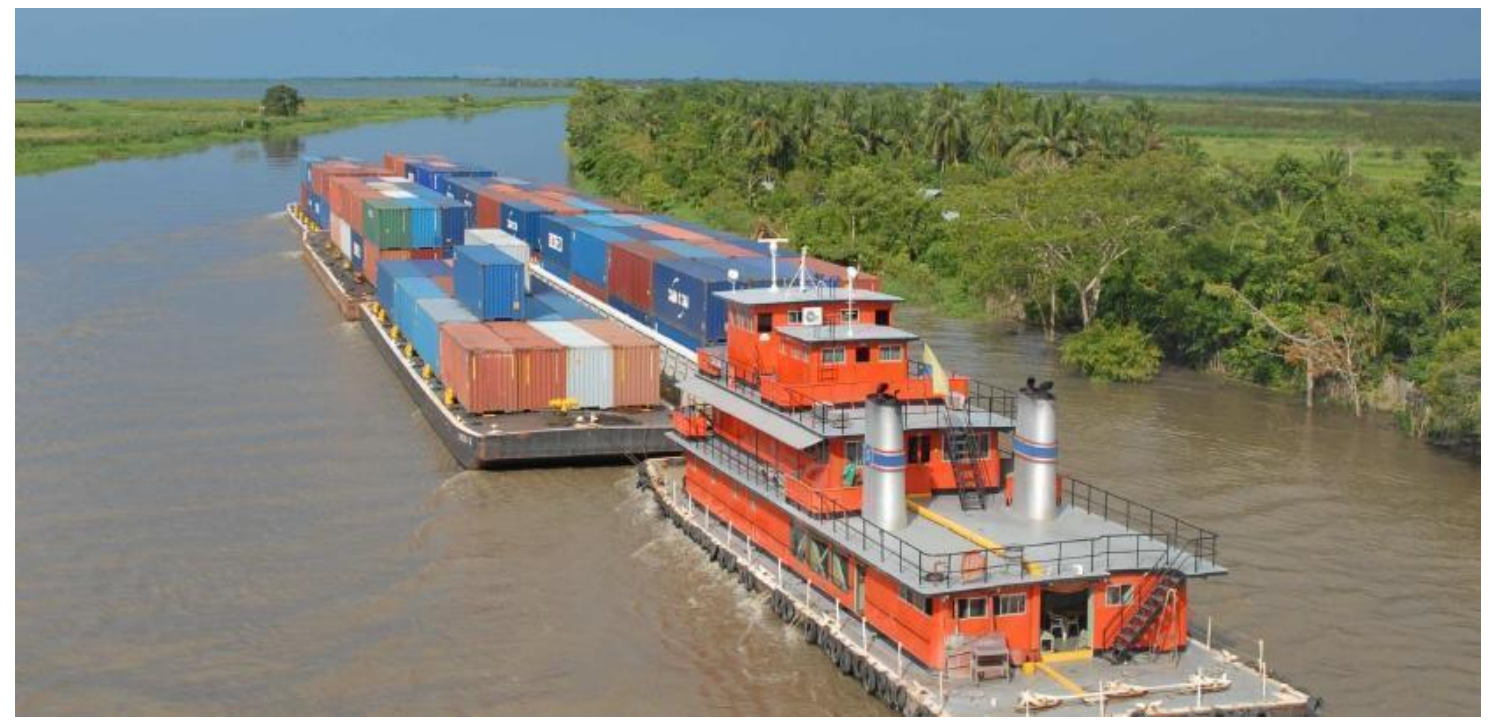

Balsa com contêineres de grãos descendo o rio Madeira

Fonte: Movimento dos Atingidos por Barragens. 
Trabalho Necessário: Como o MAB vê as ações do Estado frente o cenário do avanço das commodities?

Océlio Muniz: O MAB tem feito avaliação que a energia é uma commodity. O Estado sempre garantiu a construção de hidrelétricas e sempre garantiu a venda dessa energia para as grandes empresas - onde há o consumo de uma grande quantidade de energia e energia barata, enquanto a população paga mais caro. Uma das commodities que temos discutido é a energia elétrica, porque a partir dela outras commodities começam a se fixar espaço. Em Rondônia a construção das hidrelétricas do Madeira, abriu espaço para o avanço das commodities de monocultura no interior do estado, porque o aumento em infraestrutura atende o objetivo de ter mais energia para essas empresas. Há ainda um plano para a construção de mais duas hidrelétricas em Rondônia (Brasil-Bolívia binacional) para garantir a infraestrutura de exportação das commodities, como a carne do boi que tem muita produção para exportação e a soja, que vem avançando do sul do estado para Porto Velho, que se dá depois da construção das usinas e com grande apoio do Governo Estadual e Federal nesse fortalecimento dessas empresas de produção de commodities.

Trabalho Necessário: Quais são as críticas que devemos fazer ao projeto de desenvolvimento em curso? Qual é projeto de sociedade que o MAB defende?

Océlio Muniz: No Brasil a economia já estava indo mal antes da pandemia do vírus COVID-19. O crescimento econômico de 2019 foi o pior dos últimos anos e até aquele momento todas as medidas tomadas pelo governo não indicavam qualquer condição de retomada do crescimento econômico. Além do baixo crescimento econômico, houve uma imensa retirada de direitos que certamente agrava as condições de vida e de trabalho da maioria do povo. Estava, em grande medida, avançando muito nas privatizações de tudo (saúde, energia, petróleo, educação). Está em curso o aprofundamento do programa neoliberal, que não deu certo em nenhum país.

O MAB defende um modelo de sociedade onde todos possam ter os mesmos direitos e sermos solidários. Defendemos que a água e energia não são mercadoria, 
sejam bens públicos a serviço dos brasileiros. Defendemos uma cultura da solidariedade, na necessidade de divisão das riquezas, na necessidade de colocar a vida acima do lucro, e na articulação do país com países mais avançados com este pensamento na humanidade.

Trabalho Necessário: De que forma as populações atingidas por megaempreendimentos respondem às pressões do capital? Como as pessoas se organizam para romper com a lógica que lhes é imposta?

Océlio Muniz: Nossa luta sempre foi à luta contra as barragens. Entendemos que as barragens não servem ao povo e as comunidades. Nossa ação sempre foi coletiva buscando a compreensão política dos interesses por trás das empresas (lucro). Nossas ações começam nas comunidades: organizações de base e comunitárias, negociações coletivas e pressão popular.

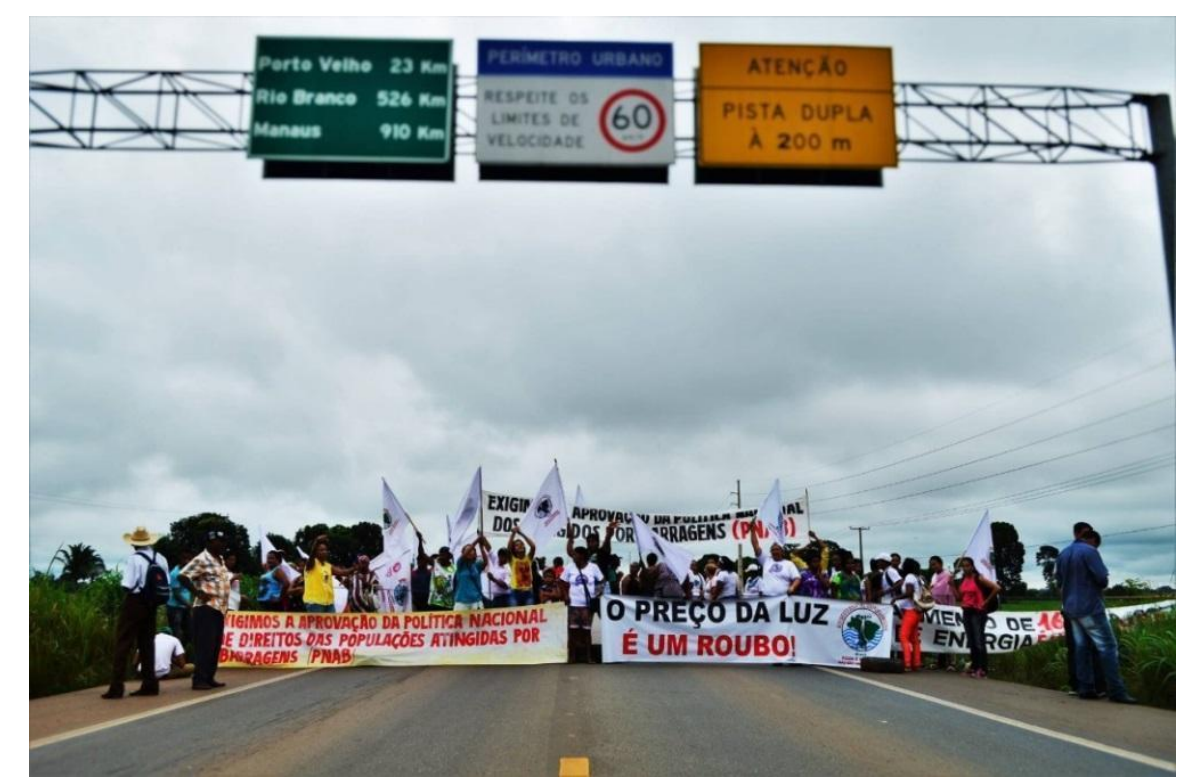

Ato mobilizado pelo MAB - RO, em 14 de março de 2015, na rodovia BR 364 , em Candeia do Jamari. Parte da luta, em defesa da soberania popular energética.

Fonte: Océlio Muniz (arquivos do MAB),

Trabalho Necessário: Sabemos que em muitos casos os atingidos por barragens não aderem à luta do MAB. Estes realizam acordos individuais e acabam recebendo compensações financeiras abaixo do que busca o coletivo. Mas, para muitos, ao compreenderem que essa compensação financeira não é compatível aos seus bens (materiais, 
mas, sobretudo aos imateriais), procuram na luta coletiva uma forma de exigir o que lhes é de direito. O que fazer com essas contradições que ocorrem dentro do movimento?

Océlio Muniz: As contradições são resolvidas no processo de formação política e no enfrentamento às empresas pela luta popular. Nossa ação se fortalece com os grupos coletivos para o processo de negociação com as empresas e o Estado. A de luta coletiva faz os atingidos percebem que as pautas são atendidas com amplitude. $\mathrm{Na}$ maioria das vezes, o distanciamento dos atingidos da luta coletiva se dá via trabalho de cooptação das empresas, que usa o seu poder econômico e político pra colocar os atingidos contra o MAB.

Trabalho Necessário: Sobre a atuação do MAB nos reassentamentos consequentes da construção das usinas de Jirau e Santo Antônio e de acordo com relatos dos moradores, a situação dessas comunidades realocadas ainda não foram resolvidas. Quais são os principais conflitos que ocorrem? Como é a vida nos reassentamentos? Os ribeirinhos conseguem manter-se nesses novos territórios?

Océlio Muniz: A nossa luta no Madeira foi pra que as comunidades tivessem suas vidas reconstruídas em novas comunidades (reassentamentos). A proposta das empresas seria unicamente as indenizações. Nossa luta obrigou as empresas adotar três modelos de compensações:

I. Reassentamentos (realocação das famílias);

II. Indenizações justas e carta de crédito;

III. Com condições estruturantes visando à melhoria da qualidade de vida e geração de renda para as famílias atingidas.

Esse processo foi de muita luta, pois as empresas não queriam entender as demandas do MAB. Avançamos uns $70 \%$ da nossa pauta. Por não atender nossa demanda, os atingidos ainda sofrem com problemas estruturantes nas áreas atingidas. Por exemplo: 
- Reserva legal: Destinação das reservas legal dos reassentamentos - ao todo são sete áreas de reassentamentos sem reserva legal, nas quais as empresas não conseguem destinar a essa função.

- Infraestrutura, abastecimento de água e saneamento básico: Nos reassentamentos não tem sistema de tratamento de água.

- Lotes alagados: Imediata negociação coletiva para solução dos lotes que foram atingidos com a formação do reservatório e encharcados.

- Assistência técnica: ampliação do período de assistência técnica para um período de no mínimo cinco anos, discutido e acompanhados pelos os atingidos.

- Plano de reestruturação e desenvolvimento da comunidade: Com ações e recursos que voltados para o acesso à água, crédito produtivo, construção/reformas de casas, uso sustentável do lago pelas famílias do projeto, reflorestamento da beira do lago.

- Programa de apoio atividade pesqueira: Implementação imediata do projeto experimental de criação de peixes em tanques escavados, conforme últimos encaminhamentos das reuniões no reassentamento de Teotônio - projeto que foi debatido e aprovado com a comunidade do reassentamento.

- Aquisição de terras para a implantação dos projetos produtivos das famílias de Teotônio.

Trabalho Necessário: Em agosto de 2019, estivemos em um reassentamento nas proximidades de Porto Velho $(\mathrm{RO})$ e, entre muitas conversas e entrevistas, uma senhora reassentada relatou que era "uma ribeirinha sem água". Atualmente, ela reside em um reassentamento que possui o lençol freático contaminado com água imprópria ao consumo. Essa senhora tem por volta de 60 anos de idade e viveu até os 52 anos na beira de um rio, possuía relações de vida e trabalho com a água, mas hoje precisa comprar água para consumir. De que forma esse afastamento forçado do território de origem impacta a saúde mental e física dos atingidos e das atingidas? Como o MAB auxilia psicologicamente essas pessoas? 
Océlio Muniz: Um dos grandes problemas das famílias foi essa distância do rio. Sempre acontece e não tem retorno. As empresas privatizam o rio e distanciam o povo de sua origem. Nossa luta sempre foi contra esse processo de remoção das famílias. As empresas têm, por obrigação, restabelecer as condições de vida dos atingidos, mas as mesmas não têm garantido esse processo. Como já relatei, tem muito a ser feito nas comunidades, desde garantir água as famílias dos acompanhamentos sociais. O MAB tem buscando parceria com universidades (como o departamento de Psicologia para tentar buscar uma solução coletiva). Também tem pressionado as autoridades e as empresas para solucionar os problemas. Os grandes responsáveis são eles, no que se refere aos empreendimentos de Santo Antônio Energia e Jirau.

Trabalho Necessário: Você falou do "Departamento de Psicologia". De qual instituição? Quais instituições, sobretudo as educacionais, são parceiras na luta do MAB? Qual o intuito de envolver a questão psicológica nas pautas dos reassentamentos?

Océlio Muniz: Refiro-me ao Departamento de Psicologia da Universidade Federal de Rondônia, que o MAB, preocupado com a questão do impacto a saúde dos atingidos (principalmente as mulheres), construiu uma parceria com a instituição para fazer um trabalho junto às companheiras do movimento, para identificar e realizar um processo em conjunto com as lutas do MAB, no qual há encontros com as mulheres atingidas, onde professores e estudantes de psicologia estão acompanhando. A ideia é conseguir mapear nas comunidades atingidas, reassentamentos e comunidades urbanas, quais ações podem ser trabalhadas com a psicologia. $O$ trabalho com a Universidade é para construir o espaço, para dentro da Universidade, que tenha necessidade de acompanhar essas questões pensando que a usina, no seu momento de construção, trabalhou. Ela contratou psicólogos para o processo de remanejamento das famílias e a nossa análise enquanto movimento de atingidos por barragens, que socializamos com a universidade que, a maioria dos psicológicos contratados, fizeram um processo de cooptação com as famílias e de convencimento de que essa ideia é mais viável para as outras comunidades. Não foi para trabalhar com o processo de reconstrução social, foi mais um processo de pressão para aceitar o projeto e não fazer questionamentos. Essa aproximação com a Universidade é para 
fazer o outro lado: questionar esse projeto feito pela usina e criar um novo e mais participativo juntamente com a psicologia rural.

Trabalho Necessário: Sobre o tema "saúde física e mental", qual o impacto ao atingido (a) quando as famílias são realocadas para regiões que nada se assemelham ao seu antigo território e seus modos de vida locais?

Océlio Muniz: $O M A B$, em seus mais de 30 anos de luta, vem identificando que o grupo que mais sofre mais com a construção das hidrelétricas é o das mulheres. Elas são as mais impactadas. Isso se dá porque é a mulher que tem o cuidado da casa, que tem a preocupação com a família e como vão reconstruir suas vidas, entre outros fatores. O movimento identificou que essa mulher quando é remanejada - sai da sua comunidade de origem passa para outro território desconhecido -, ela passa a sofrer um grande impacto social, tanto pela questão de saúde física quanto mental que, por vezes, se agravam. Há casos em que essas mulheres, ao serem remanejadas para outras comunidades, passam a sofrer de depressão e tem situações de chegarem a óbito, sem explicações ou por doenças. Com o aumento nos casos, o coletivo de mulheres do MAB tem feito um grande trabalho para essa identificação. Em Rondônia não foi diferente, tem muitas situações das comunidades atingidas reassentadas que, com a maioria das mulheres, acontece separação entre os casais, deixam o reassentamento e vão para outros territórios, porque elas não conseguem se adaptar à realidade imposta pela empresa construtora da barragem.

Trabalho Necessário: $\mathrm{Na}$ atual conjuntura, os movimentos sociais enfrentam um recrudescimento das ações que visam criminalizar as suas lutas. Tendo em conta sua experiência como atingido, militante e membro do MAB, de que maneira os ataques políticos do atual governo e as perseguições às lideranças populares, podem enfraquecer a luta coletiva? O que é preciso fazer para resistir e avançar na luta? 
Océlio Muniz: Nossa militância tem consciência do desafio na atual conjuntura, estamos na linha de fogo da luta em defesa da vida e dos direitos humanos. $O$ atual governo tem um plano claro de aniquilar os movimentos em todos os sentidos. Nosso desafio é continuar na defesa da vida e dos povos construindo unidade da luta povo. Só a luta popular pode derrotar o fascismo.

Trabalho Necessário: Como tem se dado o diálogo com outros movimentos sociais? Quem são os maiores parceiros do MAB?

Océlio Muniz: Nessa conjuntura estamos construindo uma unidade. No campo construímos a Via Campesina uma organização dos camponeses. Na cidade construímos a Frente Brasil Popular em defesa dos nossos diretos e pela democracia. No debate para um novo modelo energético construímos com os setores da energia e da água com a chamada Plataforma Camponesa, que tem como tema central a defesa de projeto energético popular pra o Brasil.

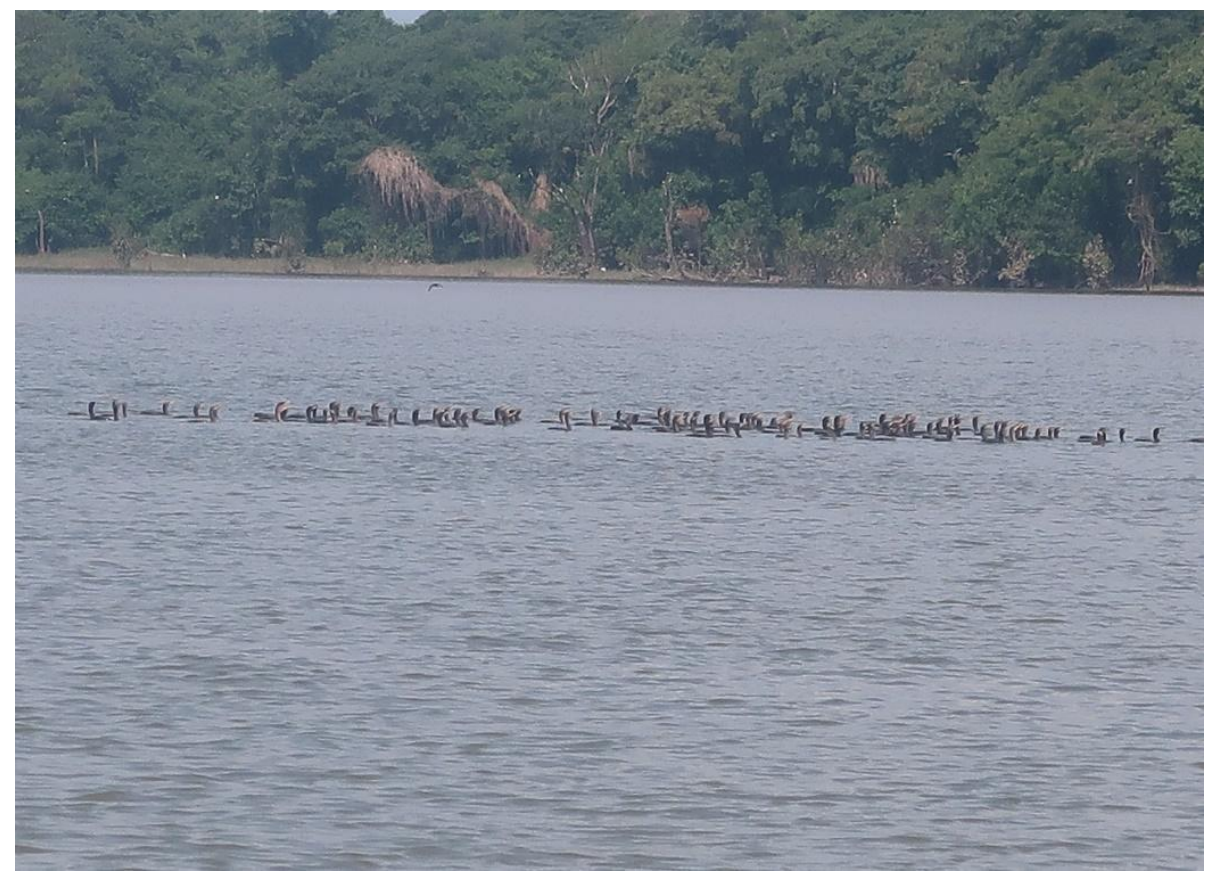

Pássaros descansam no Lago Cuniã

Fonte: Foto de William Kennedy do Amaral Souza (2019).

Trabalho Necessário: Como é o projeto energético popular para o Brasil que o MAB defende? 
Océlio Muniz: O MAB passou a discutir isso nos últimos anos. Nós passamos a discutir o modelo energético brasileiro fazendo questionamentos: energia para o quê e para quem? Barragem para o quê e para quem? Uma das respostas que estamos em processo de construção coletiva, é o "Projeto Energético Popular para o Brasil", que temos discutindo juntamente com o público urbano e do campo, com os bairros, com os sindicatos na área do setor elétrico, com os setores e agências de águas, com os setores urbanos, com Via Campesina e MST, movimentos ligados às mulheres camponesas e pequenos agricultores. A ideia é construir esse projeto popular como uma tarefa do MAB (por se um movimento ligado à questão energética), que o Brasil tenha um sistema elétrico voltado para o povo. Que a construção de hidroelétricas seja feita se o povo decidir. Que possamos apostar em outras fontes energias alternativas e que, ao mesmo tempo, questiona que nesse modelo que sociedade capitalista, qualquer projeto energético desenvolvido pelas empresas é para geração de lucro. Então queremos discutir esse lucro. Para quê e para quem esse lucro? As comunidades atingidas terão retorno? Se for necessário construir as hidrelétricas, e se for necessário: para quê para quem? O "Projeto Energético Popular" não é um projeto pronto, tem os seus eixos de energia popular, a riqueza gerada pelos empreendimentos energéticos (para onde vai?) e que as pessoas decidam e que tenham o direito de dizer não, seja pela construção da barragem ou outro tipo de projeto enérgico. O povo tem que ter o direito de dizer "não" aos empreendimentos.

Trabalho Necessário: Quais os significados da educação para organização e participação social na luta contra os crimes ambientais? Como a formação de base política se torna um importante elemento na luta e na mobilização? O que um atingido por barragem aprende quando se insere na luta?

Océlio Muniz: A educação sempre foi um elo de libertação da classe trabalhadora. Acreditamos que continua sendo um grande processo de luta contra as opressões. Quando essa educação torna-se educação política, rompemos com as secas das opressões e construímos lutas libertadoras. O atingido quando faz a luta contra as barragens, faz a luta contra o modelo capitalista de exploração da natureza. 


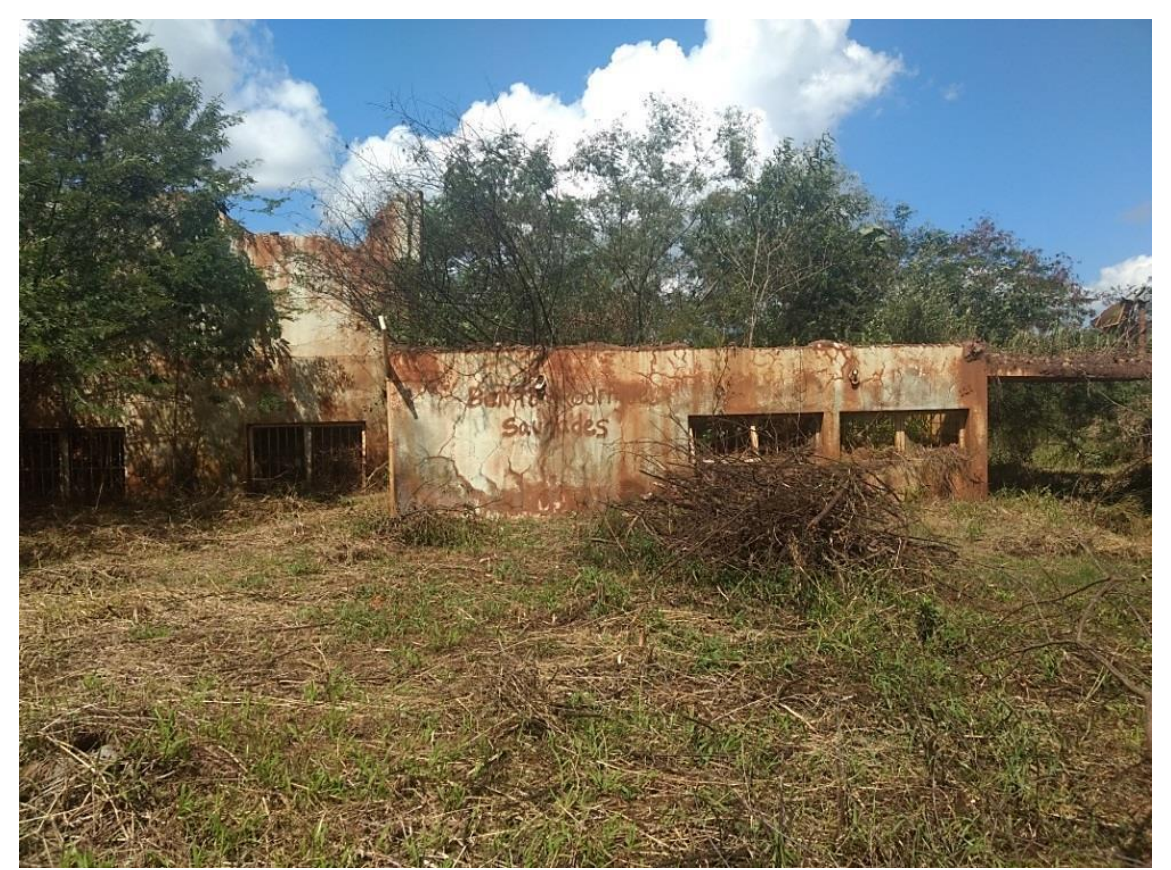

A manutenção dos espaços formativos das populações locais atingidas por barragens é parte das ações desenvolvidas pelo MAB, promovendo debates visando à unidade popular na construção de uma nova consciência ambiental crítica e na luta por direitos. No registro fotográfico, a antiga escola de Bento Rodrigues (Mariana - MG), primeiro distrito destruído pelos rejeitos de Fundão em nov./2015, com 19 mortos. Além do ensino formal, o espaço servia de encontros e atividades coletivas da comunidade.

Fonte: Mahalia Aquino (arquivo pessoal), em 06 de abril de 2019.

Trabalho Necessário: Existe um momento específico em que os(as) atingidos(as) começam a ter uma compreensão crítica de sua condição de subalternizado, de atingido ambiental e se mobilizam na luta? Em um sentido romântico, quando acontece o despertar da consciência?

Océlio Muniz: Há três momentos: o primeiro momento é quando as comunidades, antes das construções das hidrelétricas, elas se organizam ou auto se organizam, $e$ fazem o processo de luta de não deixar construir. Esse primeiro momento é mais difícil e é mais conflituoso, porque as comunidades passam por um momento de cooptação - cooptados pelo governo, por autoridades locais (vereadores, prefeitos) e também pelas empresas. Nesse ponto é mais difícil despertar da consciência, mas tem muitos casos no Brasil em que as famílias se organizam antes e não deixam fazer em nenhum empreendimento. Em Rondônia foi mais difícil, porque a maioria das comunidades atingidas ribeirinhas no Rio Madeira, não tinham acesso a políticas públicas. O primeiro acesso a programas governamentais veio com a construção das hidrelétricas, sendo um embate grande esse processo da consciência antes da 
construção da barragem. O segundo momento, no processo de construção da hidroelétrica ('não conseguimos barrar, vai sair o empreendimento'), e as famílias passam a ter consciência de que a construção vai tirar a sua vida e o seu sustento. $O$ despertar acontece pela perda, pelo sentimento da perda e esse processo começa a intensificar o processo de luta e organização no MAB, na necessidade de se organizar no coletivo e fazer luta para garantir um direito. O terceiro momento é o depois da construção da hidrelétrica, porque depois da sua construção nem tudo foi garantido, nem todo direito foi garantido. Depois do empreendimento pronto, tem muito despertar ainda - de continuar na luta, na organização do movimento e coletiva, os grupos de base -, em um processo de pressão constante. Porque o empreendimento, por exemplo, a usina de Santo Antônio Energia, elas terão uma concessão da hidrelétrica por 30 anos. Então fazemos um processo de organização em longo prazo, de que a luta vai ser permanente. Quem já despertou a consciência está nas fileiras de luta $e$ organização do MAB, quem falta despertar em um desses três momentos vai acontecer. Mas o momento chave para essa construção crítica, mais firme e constante é no segundo momento, quando se dá a construção da hidrelétrica, onde os sentimentos da perda e da impotência de fazer a luta aparecem e ficam mais visíveis.

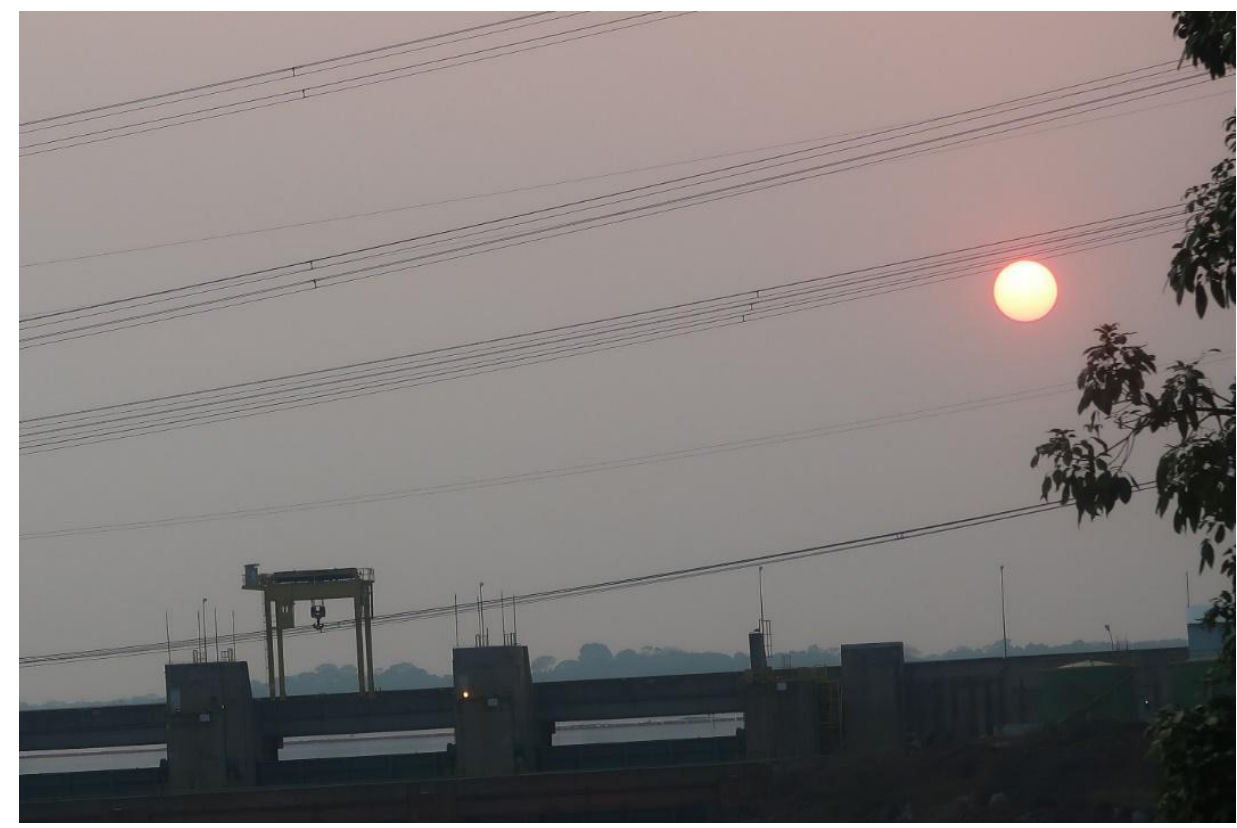

Em agosto de 2019, ruralistas convocaram o "dia do fogo". Ao fundo, o sol vermelho por conta de fumaça das queimadas. Em primeiro plano a Usina Hidrelétrica de Santo Antônio.

Fonte: Foto de William Kennedy do Amaral Souza (2019).

Trabalho Necessário: Grande parte dos atingidos por barragens vivem (ou viveram) em comunidades tradicionais, lugares onde os 
saberes são construídos na vida cotidiana, na relação com a natureza e entre si. Qual a importância desses saberes tradicionais na luta do MAB por uma sociedade melhor?

Océlio Muniz: A vida em comunidade historicamente foi coletiva: os saberes de cuidar da terra, dos rios e das florestas, como uma produção pra alimentar a vida... Esses saberes contribuem na preservação da luta e construção coletiva das pautas. Uma das grandes experiências que levamos nas nossas frentes de lutas são os grupos de famílias, onde buscamos fazer as reflexões das nossas ações. Sempre construímos mutirões de trabalhos comunitários e solidários. Os seres solidários são marcantes no processo da luta das comunidades, um valor imensurável.

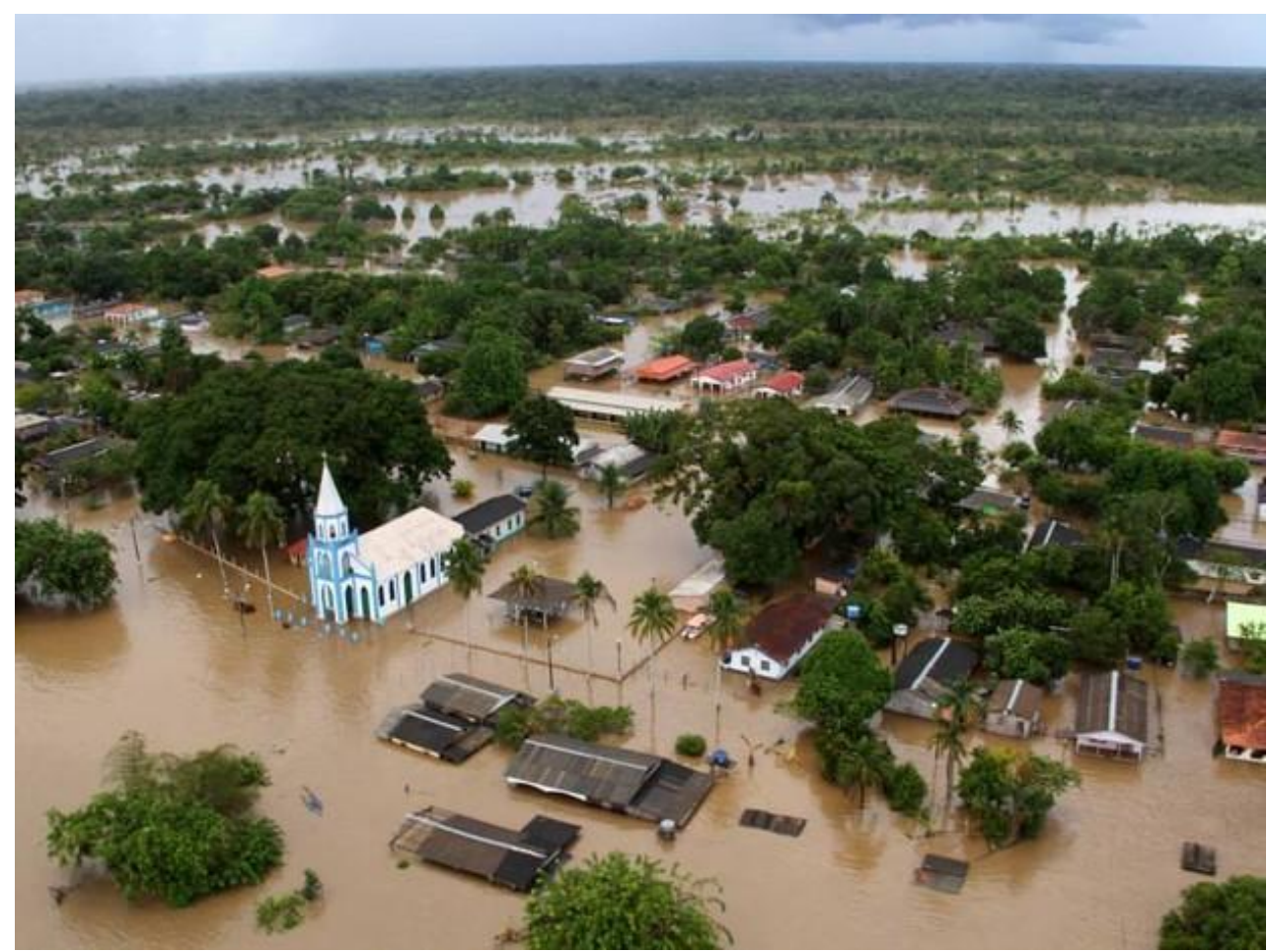

Em 2014 uma enchente colossal trouxe uma série de consequências negativas para a cidade de Porto Velho e para as comunidades ribeirinhas. Bairros e comunidades ficaram debaixo d'água por conta das inundações. E muitos especialistas afirmaram que tais inundações são impactos causados pelas usinas. Na foto, o Distrito de São Carlos do Jamari totalmente inundado pela cheia do rio Madeira. Os moradores reconstruíram a comunidade. Fonte: http://rondoniadigital.com 

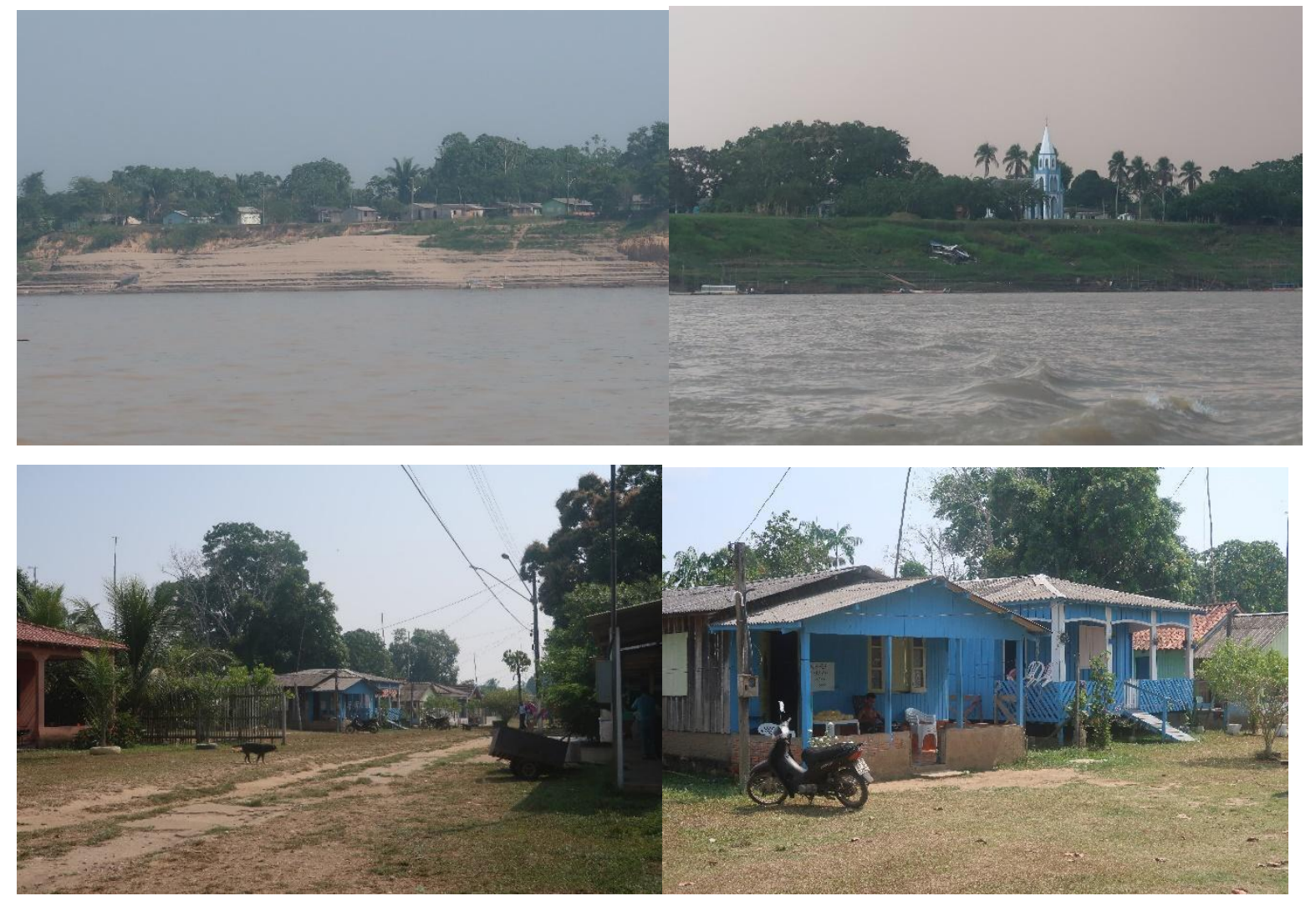

Distrito de São Carlos do Jamari reconstruído pelos moradores Fonte: Fotos de William Kennedy do Amaral Souza (2019). 